\title{
Neurite Growth Patterns Leading to Functional Synapses in an Identified Embryonic Neuron
}

\author{
David Reese and Pierre Drapeau \\ Departments of Biology and of Neurology and Neurosurgery, McGill University and Center for Research in Neuroscience, \\ Montreal General Hospital Research Institute, Montreal, Quebec, Canada, H3G 1A4
}

\begin{abstract}
We explored the relationship between neurite outgrowth and the onset of synaptic activity in the central neuropil of the leech embryo in vivo. To follow changes in early morphology and the onset of synaptic activity in the same identified neuron, we obtained whole-cell patch-clamp recordings and fluorescent dye fills from dorsal pressure-sensitive $(P)$ cells, the first neurons that could be reliably identified in the early embryo. We followed the development of the $\mathrm{P}$ cell from the first extension of neurites to the elaboration of an adult-like arbor. After the growth of primary neurites, we observed a profuse outgrowth of transient neurites within the neuropil. Retraction of the transient neurites left the primary branches studded with spurs. After a dormant period, stable secondary branches grew apparently from the spurs and became tipped with terminals. At this time, neurites of the Retzius $(R)$ cell, a known presynaptic partner in
\end{abstract}

the adult, were observed to apparently contact the terminals. Although voltage-dependent currents were seen in the P cell at the earliest stage, spontaneous synaptic activity was only observed when terminals had formed. Spontaneous release was observed before evoked release could be detected from the $\mathrm{R}$ cell. Our results suggest that transient neurites are formed during an exploratory phase of development, whereas the more precisely timed outgrowth of stable neurites from the spurs signals functional differentiation during synaptogenesis. Because spurs have also been observed in neurons of the mammalian brain, they may constitute a primordial synaptic organizer.

Key words: synaptogenesis; embryo; development; synaptic current; neurites; confocal microscopy; patch clamp
Our current understanding of cellular and molecular events during synaptogenesis is primarily based on the relatively simple and accessible neuromuscular junction. Synapse formation in the CNS entails additional complexity beyond that at the neuromuscular junction caused by the multitude of neurotransmitters, diversity of receptors, and numerous choices of potential partners for neuronal synapses. Synaptogenesis has been divided into three successive stages: initial guidance toward the target, selection of specific synaptic partners, and later refinement of connections (Goodman and Shatz, 1993). Axon guidance is mediated by a combination of primarily activity-independent mechanisms of cell attraction and repulsion by adhesive and secreted factors (Tessier-Lavigne and Goodman, 1996). Activity-dependent mechanisms are thought to predominate the later stage of synapse refinement (Katz and Shatz, 1996). A key intermediate step that remains elusive is the transition from a navigating growth cone to a functional nerve terminal. To study this ultimate step that includes partner recognition, assembly of the synaptic machinery, and excitation-secretion coupling, both morphological and physiological analyses of neuronal interactions in the developing embryo are required.

The inaccessibility of the developing CNS has limited the number of morphofunctional studies of synaptogenesis in vivo. For example, in the developing retinotectal projection of Xenopus, silent synapses have been found to precede the appearance of

\footnotetext{
Received March 30, 1998; revised May 8, 1998; accepted May 12, 1998.

This work was supported by an F.R.S.Q. Senior Research Scholarship and a grant from the Medical Research Council of Canada to P.D.

Correspondence should be addressed to Dr. Pierre Drapeau, Department Neurology, Montreal General Hospital, 1650 Cedar Avenue, Montreal, Quebec, Canada, H3G 1A4.

Copyright (C) 1998 Society for Neuroscience $\quad 0270-6474 / 98 / 155652-11 \$ 05.00 / 0$
}

evoked release (Wu et al., 1996) and may be a mechanism of plasticity in the adult nervous system (Malenka and Nicoll, 1997). In simple invertebrate preparations, a temporal correlation between neurite contact and activity-dependent communication between synaptic partners has been reported (Wolszon et al., 1995; Blagburn et al., 1996). It remains critical to characterize the precise relationship between changes in neurite growth and the establishment of spontaneous and evoked synaptic activity.

The embryonic leech provides a rare opportunity to observe progressive stages of the development of central neurons. This is because of its accessible CNS, identifiable neurons, and a segmentally reiterated nervous system displaying a rostrocaudal developmental gradient (Stent et al., 1992). Within the same embryo, each segmental ganglion is only a few hours apart in development from its nearest neighbors, permitting a high level of temporal resolution. In this study, we examined the outgrowth of neuropilar processes and the onset of synaptic activity in the pressure-sensitive $(\mathrm{P})$ cell, which is the first identifiable neuron. To follow changes in early morphology and the onset of synaptic activity, we obtained whole-cell patch-clamp recordings and fluorescent dye fills from the first extension of neurites to the development of an adult-like arbor.

\section{MATERIALS AND METHODS}

Animal care. Embryos were obtained from an in-house breeding colony. Leeches (Hirudo medicinalis) were ordered from Ricarimpex (Audenge, France) and were bred and fed according to a schedule adapted from Sineva $(1944,1949)$. To have a year-round supply of embryos, we controlled the environment of the leeches with an incubator to provide $14 \mathrm{hr}$ of light at $28^{\circ} \mathrm{C}$ and $10 \mathrm{hr}$ of dark at $26^{\circ} \mathrm{C}$. Leeches were fed a whole-blood meal every 3-5 months prepared from fresh bovine blood encased in pork intestine and warmed to $35-40^{\circ} \mathrm{C}$. After feeding, leeches were kept at $24^{\circ} \mathrm{C}$, and aquaria were filled with fresh water daily for 1 week before 


\begin{tabular}{ll}
\hline Table 1. Staging characteristics for leech embryos \\
Age & Staging characteristics \\
\hline E5 & Coalescence of germinal bands complete \\
E6 & Anterior germinal plate of same length as posterior \\
& germinal band \\
E7 & Posterior germinal band only 10\% of embryo length \\
E8 & Nephridial primordia visible in segments $4-12$ \\
E9 & Mouth no longer widest portion of body; embryo changed \\
& from fan-shaped to elliptical; all nephridial primordia \\
& visible; genital primordia appearing \\
E10 & Nephridiopores becoming white, nonprotruding heart- \\
& shaped posterior sucker \\
E11 & Outermost rim of mouth closed dorsally; caudal sucker \\
& beginning to protrude and becoming disk-like \\
E12 & Teeth visible \\
E13 & Eye spots visible but not pigmented \\
E14 & Eyes pigmented \\
\hline
\end{tabular}

leeches were isolated in jars for a period of 7-10 d in the dark. After isolation, leeches were combined into groups of three leeches per 21 container and placed in the incubator. Leeches were inspected weekly at the time of water changing for signs of gravidity that included a stiff and swollen clitellum, taking on a yellow tinge at advanced stages. Gravid leeches were placed in tilted terraria containing a shallow pool of water at one end with a gravel bottom and a humid moss bedding at the raised end for cocoon deposition. Terraria were inspected weekly for cocoons (at the time of water changing) to minimize disturbances to the colony. Cocoons were kept in separate humid containers until embryos were used for experimentation.

Staging. Embryos were staged according to criteria adapted from Fernandez and Stent (1982). Although these criteria correspond to the age of development at $25^{\circ} \mathrm{C}$, they were useful for staging embryos reared at the lower temperature of $17^{\circ} \mathrm{C}$ in this study. The staging method used progressively developing characteristics that became noticeable on particular days. The staging characteristics are outlined in Table 1.

Dissection. Embryos were removed from the cocoon using a sterile scalpel blade, then placed in $0.22 \mu \mathrm{m}$ filtered spring water (Labrador, Canada) in a Petri dish, and kept in a $17^{\circ} \mathrm{C}$ incubator. Embryos were removed from the Petri dishes using a sterile glass pipette and placed into a Sylgard-coated Petri dish containing leech embryo saline (see recording solutions below). The embryo was opened dorsally using fine forceps, and the yolk was pulled from the inner surface of the body under a dissecting microscope with both trans- and epi-illumination. The elastic yolk sac was used to stretch out the body wall evenly. The ventral side was pinned down using 0.002 inch tungsten wire (American Wire Industries) cut to $\sim 0.5 \mathrm{~mm}$ lengths. A hole was made in the midsection of the embryo, and an electrolytically sharpened tungsten wire (Conrad et al., 1993) was used to expose the chain of ganglia caudal to the incision. Additional pins were inserted in either side of each ganglion near or through the roots to provide additional stability because the preparation continued to exhibit rhythmic contractions. These contractions were reduced by bathing in cold saline $\left(5^{\circ} \mathrm{C}\right)$. Anesthetic agents commonly used in the leech embryo, such as ethanol or low concentrations of paraformaldehyde, were not used because these either interfered with seal formation or caused a reduction in the frequency of synaptic events. The nerve roots entering the periphery were crushed whenever possible. For embryos at embryonic day 12 (E12) and older, the blood sinus surrounding the nervous system was removed using the sharpened tungsten wire.

After the primary dissection, E12 and older embryos were dissected further under a $40 \times$ water immersion lens. The web-like developing glial cells were removed using a microhook (El-Badry, 1963) guided with a micromanipulator. If additional clearing was required, a patch electrode filled with extracellular solution was used in combination with the microhook to lift the glial "net" and blow away debris. Older embryos were too difficult to clean for patch clamping, and the neurons were too small for stable intracellular recording.

Cellular morphology. To preserve morphological integrity and allow visualization of the small caliber transient branches, we performed all cell fills in the living embryo. To minimize photobleaching, we imaged all neurons on the microscope stage without fixation. For the purposes of this study, experiments were undertaken with the dorsal $\mathrm{P}$ cell because this was the first neuron that we could recognize in the embryo based on its unique morphology, which was the presence of a conspicuous nucleolus, the large size and position of the soma, and its characteristic branching pattern once labeled. Living $\mathrm{P}$ cells were labeled during whole-cell patch-clamp recordings by including $2 \%$ Sulforhodamine B (Sigma, St. Louis, MO) in the pipette solution (see below). Cells were photographed immediately after recording on a standard epifluorescence microscope (Nikon Labophot). A CCD camera (Panasonic) was used for low-light intensity imaging of transient branches. Low-light image acquisition was performed using a custom-made stepping motor that was triggered by computer to step at $2 \mu \mathrm{m}$ intervals through the ganglion by turning the focus knob. To reduce noise, we averaged 4-32 frames in each optical section using National Institutes of Health Image software. After image capture, three sections were chosen based on clarity and detail to show the upper, middle, and lower neuritic tree. This procedure allowed a full series of optical sections to be collected quickly to determine the complete branching pattern of the neuron.

In some experiments we examined by confocal microscopy the sites of apparent contact between the $\mathrm{P}$ cell and one of its known presynaptic partners the Retzius ( $R$ ) cell. To label the $P$ and $R$ cells, we filled each neuron in vivo with a different fixable, fluorescent dye with nonoverlapping spectra. For these more demanding experiments, sharp microelectrodes containing dye at the tip were used to impale the cells with current steps of $\pm 0.4 \mathrm{nA}$ at $0.5 \mathrm{~Hz}$ followed by a $0.1 \mathrm{nA}$ pulse of $100 \mathrm{msec}$ in duration of the opposite polarity to prevent clogging of the electrode tip. $\mathrm{R}$ and $\mathrm{P}$ cells were filled with either Lucifer yellow $(3 \% \mathrm{w} / \mathrm{v}$; Molecular Probes, Eugene, OR) or Rhodamine dextran (5\% w/v; molecular weight, 3000; Molecular Probes), respectively, dissolved in distilled water. Electrodes were backfilled with either $0.2 \mathrm{M} \mathrm{KCl}$ (Rhodamine dextran) or 0.2 $\mathrm{M} \mathrm{LiCl}$ (Lucifer yellow). The embryos were then fixed in $4 \%$ paraformaldehyde for $30 \mathrm{~min}$ and mounted in SlowFade (Molecular Probes). A confocal laser-scanning microscope (Leica Canada) was used to obtain optical sections at $1 \mu \mathrm{m}$ intervals. The regions of interest were imaged twice, selectively exciting one dye at a time, and optical sections taken at the same level were combined to render a full view of both cells. Contact was estimated by inspection of each section to determine whether the neurons were apposed in more than one plane.

Whole-cell patch-clamp recordings. Whole-cell patch-clamp recordings were performed (Horn and Korn, 1992) under visual guidance with a $40 \times$ water immersion objective (Nikon) with Hoffman modulation optics (Modulation Optics). Recordings were obtained with an Axoclamp-2A amplifier (Axon Instruments, Foster City, CA). Micropipettes were pulled from borosilicate glass and fire polished to give a resistance of 5-10 M $\Omega$. Gigaohm seals were obtained by releasing a positive pressure applied while approaching the cell, and the whole-cell configuration was achieved by pulses of suction delivered by mouth. All cells analyzed in this report had input resistances $>1 \mathrm{G} \Omega$. The resting potential was between -65 and $-55 \mathrm{mV}$ at stages less than E10 and was between -55 and $-45 \mathrm{mV}$ in all embryos with stable recordings at E12 and older using physiological solutions.

The external solution in all experiments was leech embryo Ringer's solution containing $20 \mathrm{~mm} \mathrm{NaCl}, 4 \mathrm{~mm} \mathrm{KCl}, 1.8 \mathrm{~mm} \mathrm{CaCl}_{2}, 40 \mathrm{~mm}$ $\mathrm{Na}_{2}$-malate, $10 \mathrm{mM} \mathrm{Na}_{2}$-succinate, and $10 \mathrm{~mm}$ Tris- $\mathrm{HCl}$, set to $\mathrm{pH} 7.4$ and 200 mOsm (Wenning and Calabrese, 1991). The external solution was kept at $10^{\circ} \mathrm{C}$ to decrease spontaneous contractions. To block evoked

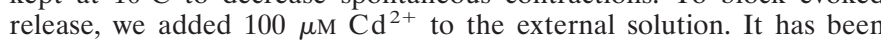
shown that this concentration of $\mathrm{Cd}^{2+}$ blocks synaptic transmission between adult leech neurons in culture (Stewart et al., 1989).

Five internal recording solutions were used to isolate currents selectively. (1) Physiological solution containing $20 \mathrm{~mm} \mathrm{NaCl}, 65 \mathrm{~mm}$ K-gluconate, $1 \mathrm{~mm} \mathrm{MgCl}_{2}, 10 \mathrm{~mm}$ EGTA, and $10 \mathrm{~mm}$ HEPES was used. (2) A high $\mathrm{Cs}$ and low $\mathrm{Cl}$ solution containing $20 \mathrm{~mm} \mathrm{CsCl}, 65 \mathrm{~mm}$ $\mathrm{Cs}_{2} \mathrm{SO}_{4}, 1 \mathrm{~mm} \mathrm{MgSO}$, $10 \mathrm{~mm}$ EGTA, and $10 \mathrm{~mm}$ HEPES was used to obtain lower noise recordings at physiological $\mathrm{Cl}^{-}$levels. (3) A high $\mathrm{CsCl}$ solution containing $120 \mathrm{~mm} \mathrm{CsCl}, 1 \mathrm{~mm} \mathrm{MgSO}_{4}, 10 \mathrm{~mm}$ EGTA, and $10 \mathrm{~mm}$ HEPES was used to reveal chloride currents selectively. (4) A high $\mathrm{KCl}$ solution containing $120 \mathrm{mM} \mathrm{KCl,} 2 \mathrm{~mm} \mathrm{Mg}-\mathrm{ATP}, 0.1 \mathrm{~mm}$ Mg-GTP, $5 \mathrm{~mm}$ glutathione, $10 \mathrm{~mm}$ EGTA, and $10 \mathrm{~mm}$ HEPES was used to detect spontaneous currents carried by $\mathrm{K}^{+}$. (5) Perforated-patch recording solution had the same composition as the high $\mathrm{Cs}$ and low $\mathrm{Cl}$ solution with the addition of an aliquot of a nystatin (Sigma) stock 


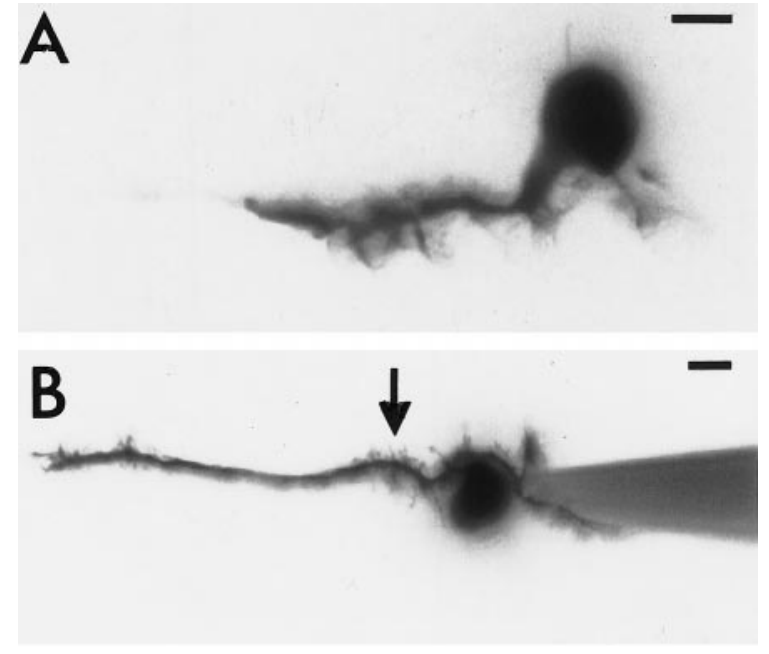

Figure 1. Extension of primary neurites. Photomicrographs of E7 dorsal $\mathrm{P}$ neurons filled with Sulforhodamine $\mathrm{B}$ at the earliest stage examined are shown. $A, \mathrm{P}$ cell from a ganglion showing axial growth cones on the anterior neurite with conspicuous lamellipodia. In this and subsequent figures, anterior is to the left. $B, \mathrm{P}$ cell from a ganglion two segments rostral in the same embryo used in $A$. The posterior neurite has partially formed and can be seen alongside the electrode (right). Filopodia are seen primarily in the ganglionic regions and are relatively absent from the neurite passing through the anterior connective (left). A characteristic inflection is seen near the soma (arrow). Scale bars, $20 \mu \mathrm{m}$.

solution $(60 \mathrm{mg} / \mathrm{ml}$ in DMSO) diluted 250 -fold. Electrodes used for perforated-patch recordings contained a nystatin-free solution in the tip to reduce bath contamination resulting from the positive pressure on approaching the cell. All internal solutions were set to $\mathrm{pH} 7.0$ and 190 mOsm or to $180 \mathrm{mOsm}$ when $2 \%$ Sulforhodamine B was included in the recording pipette to label the cell. All recordings with dye in the internal solution were performed with Trolox $\left(10^{-5} \mathrm{M}\right)$ (Sigma) (Glazer, 1988) in the dark to avoid phototoxicity. Fluorescent light exposure of up to $5 \mathrm{~min}$ did not noticeably affect neuron activity at the light intensities used during imaging with Trolox in the bath.

Data were filtered at $10 \mathrm{kHz}$ and stored by digitization at $40 \mathrm{kHz}$ on videotape (Neurodata) for off-line analysis; the data were played back to the computer and digitized at $10 \mathrm{kHz}$. The data were captured and analyzed using Axograph 3.5 and pClamp 5.5 software (Axon Instruments)

\section{RESULTS}

Because we were interested in the roles of cell-cell contact and neuronal activity in the formation of central synapses in vivo, we examined both the morphology and the physiology of the first pair of synaptic partners that can be reliably identified in the embryonic ganglion, the dorsal $\mathrm{P}$ neurons and the ipsilateral $\mathrm{R}$ neurons. We did not examine the ventral $\mathrm{P}$ neurons and refer only to the dorsal $\mathrm{P}$ neuron when we describe the "P neuron" in this report. We describe in turn below our morphological and physiological observations.

\section{Morphology}

The leech embryo develops over a $30 \mathrm{~d}$ period. During the first half of development, there is a rostrocaudal gradient such that the head is older than the tail by $\sim 3 \mathrm{~d}$ (Stent et al., 1992). In essence an early embryo spans $\sim 10 \%$ of the developmental period, and each segmental ganglion differs from its neighbors by $\sim 3 \mathrm{hr}$ $(\sim 0.5 \%)$. The neuropil of the ganglion is formed by the growing processes of the central neurons. The neurons are born on day 5 of development (E5) and start extending neurites at E7 (Fernandez and Stent, 1982) (Fig. 1). At this stage, both the P and the R cells were identifiable, and we were able to fill and record from these neurons using patch electrodes as early as E7 in the tail region, i.e., at the onset of neurite outgrowth. We describe below our detailed observations with $\mathrm{P}$ and $\mathrm{R}$ cells examined from $\mathrm{E} 7$ to E14, when the neuropilar branches reached a stage similar to that seen in the adult and synapses had formed in all neurons examined. At later stages, we were unable to obtain recordings because of glial proliferation that prevented gigaohm seal formation.

For our purposes, the morphological changes during the development of the neuronal arbor of the $\mathrm{P}$ cell could be divided into three stages. The first stage was marked by the outgrowth of the primary branches through the connectives to neighboring ganglia and into the peripheral roots. The second stage began when transient neurites grew from the primary branches within the neuropil. These branches were later retracted as spurs as the neurons appeared to enter a dormant period. The third stage of outgrowth was the production of stable neurites that appeared to grow from the spurs toward the midline, yielding an adult-like morphology. Eventually this set of stable neuropilar processes formed terminals, which occurred when synaptic currents were first detected.

\section{Primary outgrowth}

The first neurite to extend from the P cell appeared on E7 and traveled anteriorly near the midline of the ganglion (Fig. 1A). The shaft of the neurite and occasionally the soma were speckled with flattened growth cones that had elaborated lamellipodia and filopodia. After the neurite had left the ganglion to enter the connective, its morphology changed to a spiked shape, suggesting growth rather than exploration. After it had reached the adjacent ganglion, within the same day of development, the exploratory morphology was regained. The characteristic inflection in the anterior neurite near the soma was formed at this early outgrowth stage (Fig. 1B, arrow), presumably from growth around neighboring somata. Near the time at which the anterior neurite reached the adjacent ganglion, a second neurite began to extend posteriorly from the soma (seen at the edge of the pipette in Fig. 1B). Confocal imaging revealed a third neurite extending from underneath the soma that is hidden in Figure 1 (described below for Fig. 2). This neurite projected ipsilaterally to the periphery where it pioneers the dorsal nerve root (Kuwada, 1985). Eventually the $\mathrm{P}$ cell branching pattern changed from tripolar to the monopolar appearance characteristic of adult leech neurons, as the soma was displaced from the branch point in the expanding neuropil.

The R cell was monopolar from the earliest stage examined and extended several primary branches. The two posterior branches of the R neuron followed two of the primary neurites of the $\mathrm{P}$ cell along the posterior connective and dorsal root within the ganglion (Fig. $2 a$ ) and into the periphery (Gan and Macagno, 1995b). The $\mathrm{R}$ cell also had several anterior branches at early stages. One of these extended along the anterior connective, and several (two to four depending on the embryo) extended laterally toward the roots. Eventually all but two of these lateral branches were retracted, leaving only the anterior root and (as described above) posterior root branches that are retained at later stages (Jellies et al., 1987). Figure $2 a$ shows an example of the branching patterns for $\mathrm{R}$ and $\mathrm{P}$ cells in which the $\mathrm{R}$ cell had three lateral branches. The short branch was retracting (arrow) because it was shorter or absent in $\mathrm{R}$ cells of more rostral ganglia and was longer in more caudal ganglia examined in the same embryo (data not shown). 

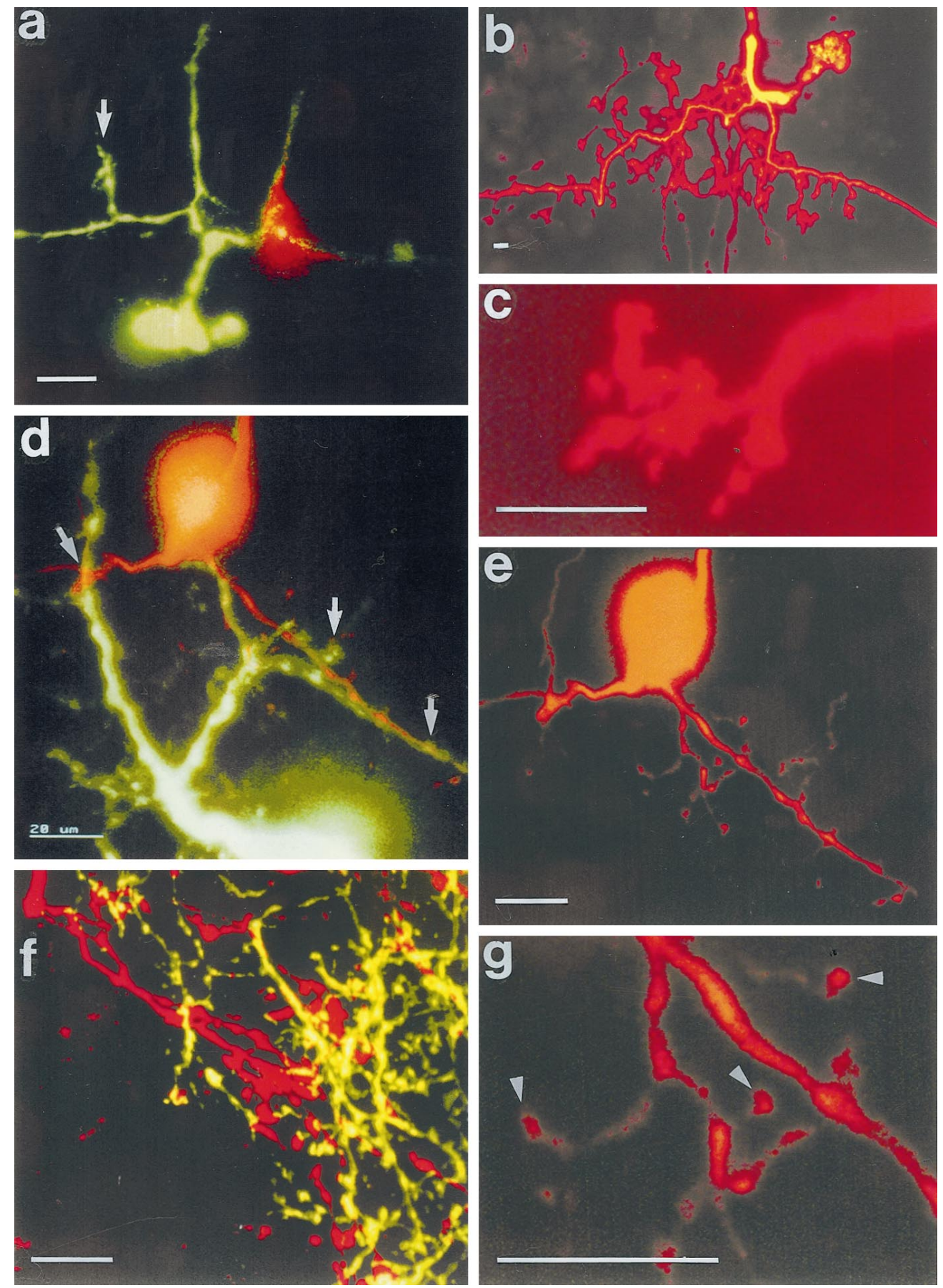

Figure 2. Contact between $\mathrm{R}$ and $\mathrm{P}$ cells and formation of terminals. In each micrograph, the $\mathrm{P}$ cells were filled with Rhodamine dextran, and in $a, d$, and $f$, the $\mathrm{R}$ cells were filled with Lucifer yellow using intracellular microelectrodes. $a$, Posterior branches of the $\mathrm{R}$ cell in an E8 embryo seen to follow the $\mathrm{P}$ cell branches to the periphery and posterior connective. The arrow indicates retraction of an anterior, lateral branch. $b$, Photomicrograph of an adult $\mathrm{P}$ neuron showing complex terminals with clusters of swellings. $c$, Enlargement of $b . d, e, g$, Confocal images of $\mathrm{R}$ and $\mathrm{P}$ cell contact in an E13 embryo. Sites of contact (imaged in $40 \times 1 \mu \mathrm{m}$ steps) were observed on each terminal of the P cell ( $d$; two indicated by arrows), seen on its own $(e)$, and enlarged ( $g$; arrowheads point to terminals). $f$, Confocal image of $\mathrm{R}$ and $\mathrm{P}$ cell processes in the adult. Note the many sites of contact. Scale bars, $20 \mu \mathrm{m}$.

\section{Transient outgrowth}

Long, thin, transient neurites extended from $\mathrm{P}$ cells in a radial fan formation into the neuropil of E9-E10 embryos. Because of their very small caliber, we had to resort to detection using a CCD camera to minimize bleaching of the processes while acquiring a permanent image. These neurites bleached within seconds, precluding a time-lapse study that would certainly confound morphological changes with phototoxic effects of the dye. In some cases, a hairy halo of neurites was observed, but more typically only a few were seen. Interestingly, these transient neurites were not observed to cross the midline, where they appeared to turn (Fig. $3 A$, arrow). Although transient neurites were repeatedly observed at this stage, their appearance did not follow the developmental gradient. In some embryos, only a few ganglia had $\mathrm{P}$ cells with transient neurites, whereas in other embryos, the majority of $\mathrm{P}$ cells displayed them. We were unable to correlate the appearance of these transient neurites between embryos in the same or neighboring segments. Even within the same ganglion, we often observed transient neurites on one $\mathrm{P}$ cell but not on its ganglionic homolog. These transient neurites therefore did not seem to follow a segmentally regionalized signal. Rather they appeared along the entire developmental gradient (although not in all segments) over a narrow time window of several $(<12)$ hours and were thus short-lived. After the retraction of these transient neurites, the primary branches were studded with spurs (Fig. 3B, arrows), perhaps as remnants of a subset of retracted transient 

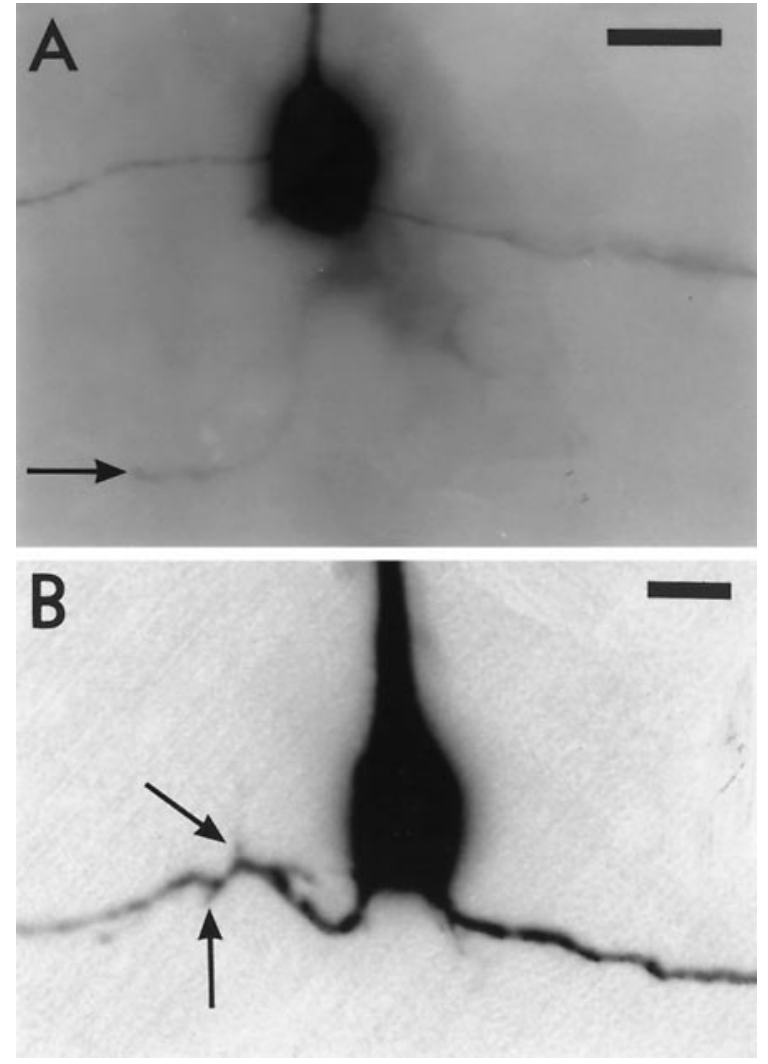

Figure 3. Outgrowth and retraction of transient neurites and formation of spurs. Intracellular fills of P neurons with Lucifer yellow in E9 embryos are shown. $A$, Photomicrograph showing a transient neurite turning anteriorly at the midline (arrow). B, Confocal image of spurs remaining after the retraction of transient neurites (arrows). The cell was imaged in $20 \times 1 \mu \mathrm{m}$ steps. Note tripolar morphology at this stage. Scale bars, 20 $\mu \mathrm{m}$.

neurites. Afterward, a period (between stages E10-E11) elapsed in which the $\mathrm{P}$ cell was dormant but retained the spurs, which appeared to be the sites for the next phase of neurite outgrowth. Because the appearance of the transient branches was not segmentally correlated, the onset of the dormant period could not be determined. We can nevertheless say with certainty that the ending of this period (defined as outgrowth of stable neurites) was correlated with the developmental gradient, thus likely under control of a segmental timing signal.

Although lateral branches of the $\mathrm{R}$ cell were observed to retract (as described above), these resembled more closely the lateral branches that eventually entered the roots rather than the transient neurites of the $\mathrm{P}$ cell described above. We were unable to document whether or not transient neurites were formed in the $\mathrm{R}$ cell because of the difficulty in recognizing and filling $\mathrm{R}$ cells, which are smaller than the P cells in early embryos.

\section{Stable neuropilar processes}

The stable, second-order branches of the $\mathrm{P}$ cell began to appear after the dormancy period (on E11; Fig. 4A), and their outgrowth was well correlated with the developmental gradient, unlike the extension of transient neurites described above; i.e., stable neurite formation was increasingly developed toward the head of the embryo. These neurites grew toward the core of the neuropil and likely came from the spurs left by the transient filopodia because they appeared as the spurs disappeared from similar sites along

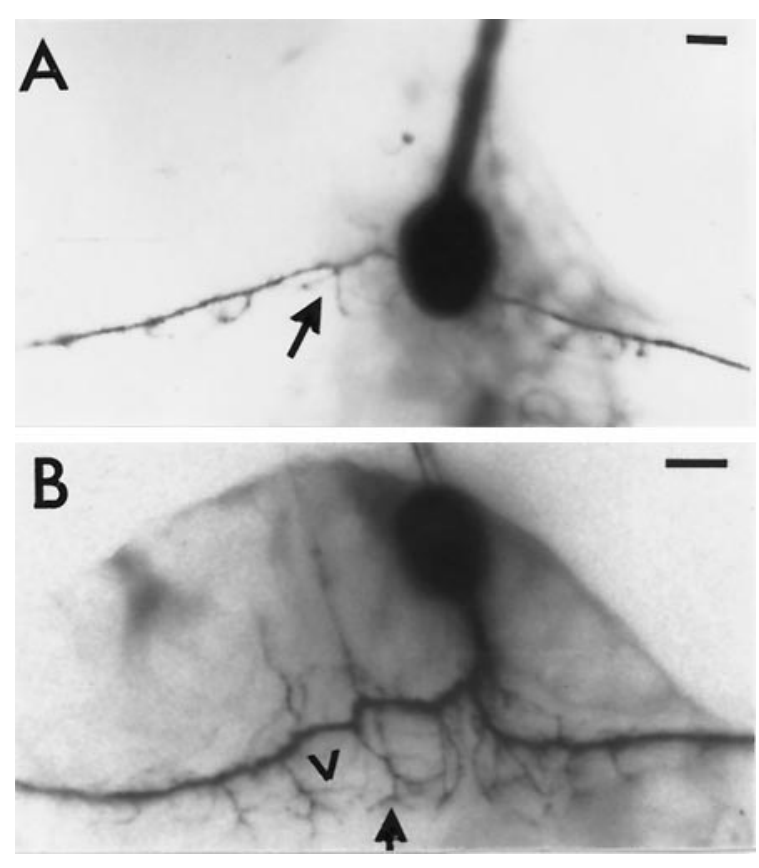

Figure 4. Outgrowth of secondary branches. $\mathrm{P}$ cells were filled with Sulforhodamine B using whole-cell electrodes. $A$, V-shaped secondary branches (arrow) seen extending from a spur on the anterior primary neurite of a E11 P cell. $B$, Y-shaped secondary branches (arrow) with finer neurites (arrowhead) in a E14 P cell. Scale bars, $20 \mu \mathrm{m}$.

the primary neurites. Some neurites were observed to grow directly from the spurs (Fig. 4A, arrow), indicating these as the possible sites of regrowth after dormancy. The initial secondorder branches appeared "V" shaped, splitting immediately after leaving the primary branches (Fig. $4 A$, arrow). This $\mathrm{V}$ shape appeared eventually to become "Y" shaped as the secondary branches were interpreted to be drawn into the expanding neuropil (Fig. 4B, arrow). As a result, the shafts of these branches came to resemble the secondary processes seen in the adult, and the distal bifurcations resembled tertiary branches, although they formed earlier than did the shafts.

As the secondary outgrowth completed itself, finer branches began to form (Fig. 4B, arrowhead). Despite this new growth in E14 embryos, the latest stage examined, the neuropilar branching pattern was far less complex than that seen in the adult (Fig. 2b), indicating that additional branching occurs after this stage, as described for other neurons (DeRiemer and Macagno, 1989). The tips of the stable embryonic processes (Fig. 2e) formed terminal swellings (Fig. $2 g$ ) that were less complex than those observed in the adult (Fig. 2c). It was during this time that the onset of miniature synaptic currents was observed, as described in the next section.

At the time that terminals were formed, the $\mathrm{P}$ cell was observed to apparently come into contact with the $\mathrm{R}$ cell. This is illustrated in Figure $2 d$ (same $\mathrm{P}$ cell seen in Fig. $2 e$ ) where the terminals of the $\mathrm{P}$ cell were imaged by confocal microscopy (enlarged in Fig. $2 g$ ). A site was marked as a terminal only if its diameter increased over two adjacent sections at the terminal ending of a neurite, as assessed by inspection of images in single focal planes $(1 \mu \mathrm{m}$ in thickness) through the $40 \mu \mathrm{m}$ optical plane. Close apposition or apparent contact at the light microscopic level was observed between the $\mathrm{R}$ and $\mathrm{P}$ cells at the $\mathrm{P}$ cell terminals (Fig. $2 d$, arrows), as assessed by overlap of the spectra of the dyes used to label each 
A
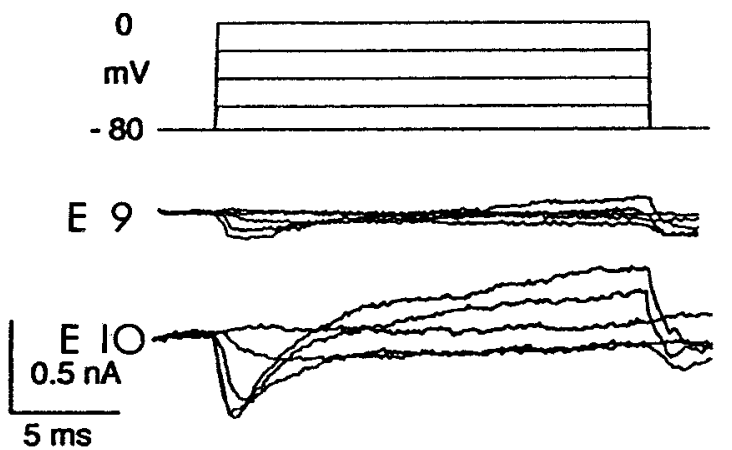

B

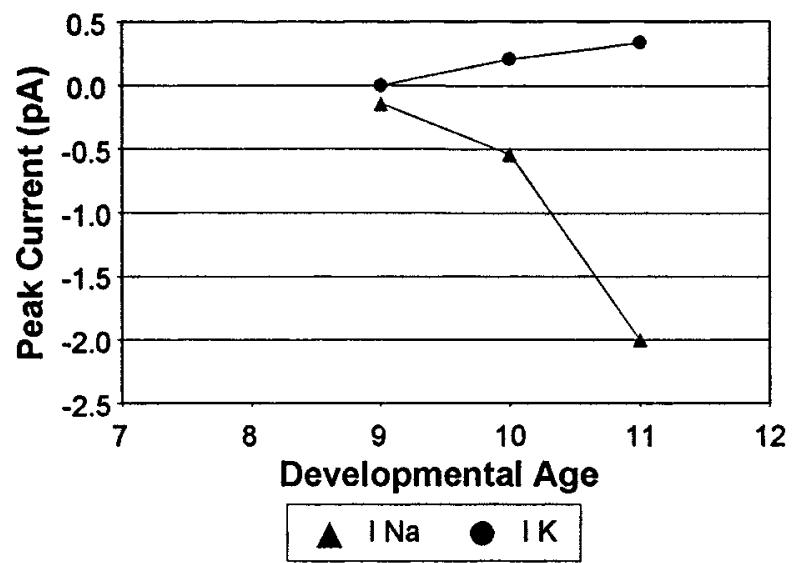

Figure 5. Development of voltage-sensitive currents. Whole-cell patchclamp recordings using physiological solution reveal voltage-sensitive currents at the first outgrowth of neurites. A, Sample traces showing the voltage steps protocol (top) from E9 (middle) and E10 (bottom) embryos with voltage-sensitive currents. $B$, Development of voltage-sensitive currents in a group of sibling embryos; mean $\pm \mathrm{SD}$ for three embryos for each measure. $I_{\mathrm{Na}}$ was estimated from the peak inward (downward) current, and $I_{\mathrm{K}}$ was estimated from the steady current level at the end of the depolarizing voltage steps.

neuron (Rhodamine dextran in the $\mathrm{P}$ cell and Lucifer yellow in the $\mathrm{R}$ cell). The mature endings of $\mathrm{R}$ (Fig. $2 f$ ) and $\mathrm{P}$ (Fig. $2 b, f$ ) cells in adult ganglia showed a larger elaboration of fine processes. As shown in Figure $2 c$, adult $\mathrm{P}$ cell terminals were present as clusters of endings that were juxtaposed to the endings of $\mathrm{R}$ cells (Fig. 2f).

\section{Physiology}

Whole-cell patch-clamp recordings were obtained from $\mathrm{P}$ and $\mathrm{R}$ cells at different developmental stages from E7 to E14. The P cells were examined in detail for the appearance of voltage-dependent currents, spontaneous synaptic events, and synaptic activity evoked by stimulating the $\mathrm{R}$ cells in dual neuron recordings.

\section{Development of voltage-sensitive currents}

Spontaneous action potentials were not observed in $\mathrm{P}$ or R cells, indicating a low level of activity if not silent neurons in early embryos (E7-E14). However, at the earliest stages recorded (E7; $n=6$ ), all neurons had voltage-sensitive currents that could be evoked by voltage-clamp steps (Fig. $5 A$ ) using a physiological pipette solution (Materials and Methods). To examine the development of voltage-sensitive currents, we measured these in sibling embryos and in similar regions of the nerve cord to avoid differ-

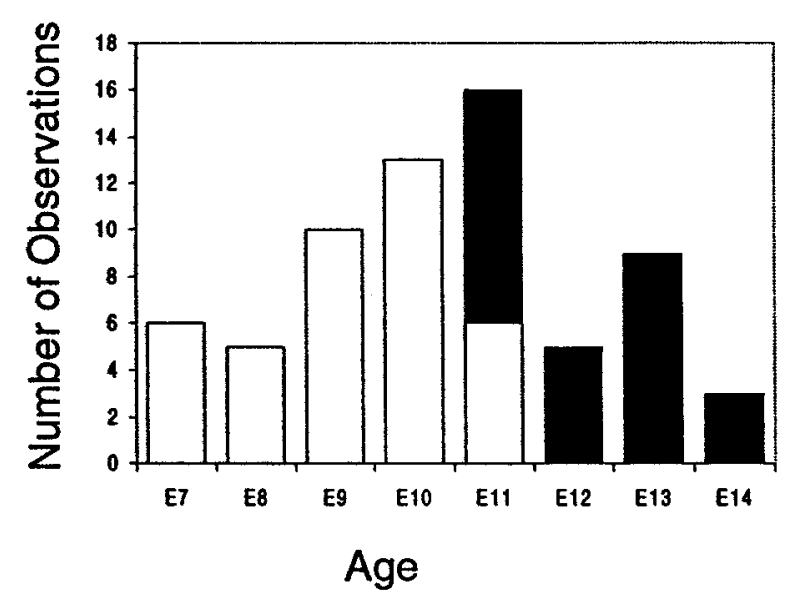

Figure 6. Summary of synaptic activity. Histogram plotting the number of recordings obtained from $\mathrm{P}$ cells at different embryonic days is shown. Open bars represent recordings without synaptic activity, and filled bars denote the presence of spontaneous synaptic events. Note that at E11 a fraction of the $\mathrm{P}$ cells displayed synaptic activity for the first time.

ences in the developmental gradient. In one experiment (Fig. 5B), maximum current amplitudes were measured in three sets of sibling embryos examined on each of 3 consecutive days of development. On E9, the sodium currents had a peak amplitude of $-147 \pm 5 \mathrm{pA}$ (Fig. $5 B)$ that increased rapidly by E11 and was subsequently too large (over $-2 \mathrm{nA}$ ) to clamp accurately and generated action potentials. The potassium current was undetectable on E9 and appeared to increase linearly to $334 \pm 4 \mathrm{pA}$ at E12.

\section{Onset of synaptic activity}

The onset of spontaneous synaptic activity was measured in $67 \mathrm{P}$ cells between E7 and E14 as summarized in Figure 6. Spontaneous synaptic currents were observed in none of the $34 \mathrm{P}$ cells recorded at E10 or younger, in 6 of $16 \mathrm{P}$ cells at E11, and in all 17 $P$ cells examined between E12 and E14. Because E11 seemed to be the transition period for synapse formation, we examined the morphology of the central neurites of the $\mathrm{P}$ cell at this stage. Of the $16 \mathrm{P}$ cells examined, 5 of 10 neurons without synaptic activity and 4 of 6 neurons with synaptic activity were sufficiently well stained to evaluate their fine morphology by briefly examining the cells through the microscope at the end of the experiment in order not to overexpose them during the fragile recordings. None of the five neurons lacking synaptic activity had terminals on their stable neurites, whereas all four neurons with synaptic activity had terminals. This is a clear indication that synapses were coincident with the presence of terminals that we conclude to be their morphological counterpart.

Using a physiological pipette solution (see Materials and Methods), synaptic currents were of low amplitude and often resulted in an increased fluctuation of the basal current level without clear synaptic profiles. To better resolve the synaptic currents (e.g., for the experiments summarized in Fig. 6), we tried pipette solutions with different ionic compositions and found that high intracellular $\mathrm{Cl}^{-}$(either with $\mathrm{K}^{+}$or $\mathrm{Cs}^{+}$as the counterion) gave the best resolution, indicating that most, if not all, spontaneous events were $\mathrm{Cl}^{-}$-dependent and thus IPSCs. Figure 7 shows examples of recordings using high $\mathrm{CsCl}$ pipette solution at $\mathrm{E} 10$ (Fig. 7, top), where no activity was detected, and in an embryo at E11 (Fig. 7, middle), where spontaneous synaptic events were clearly resolved, as shown in the expanded trace at the bottom. 


\section{E10}
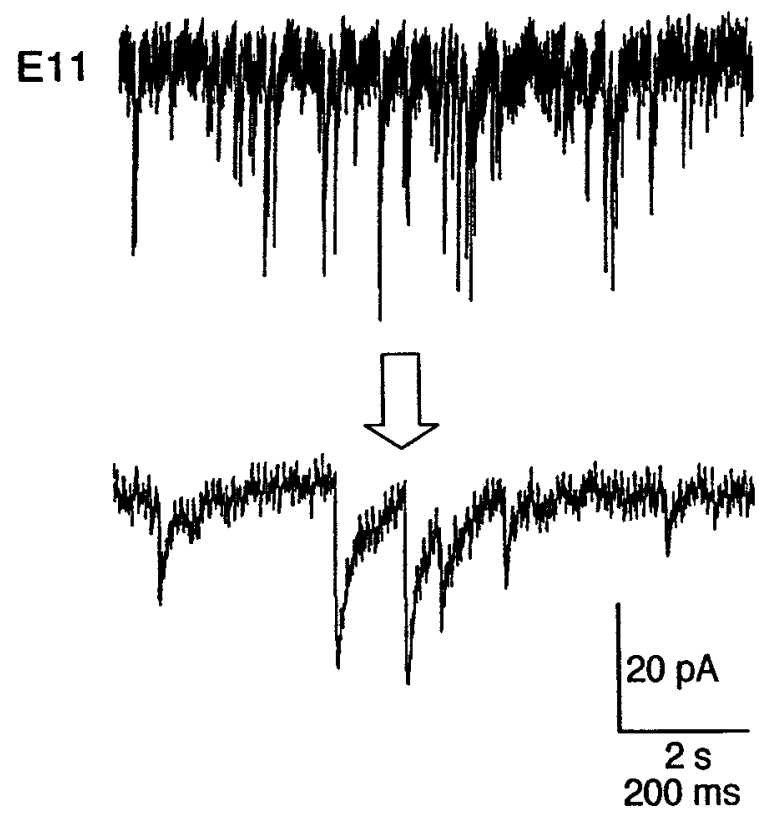

Figure 7. Onset of spontaneous synaptic activity. Top, Recordings with high $\mathrm{CsCl}$ pipette solution from a $\mathrm{P}$ cell in an E10 embryo showed no spontaneous synaptic activity. Middle, Spontaneous activity was first observed in E11 embryos. Bottom, An expansion from the $\mathrm{P}$ cell recording at E11 is shown.

\section{Spontaneous events are miniature IPSCs}

The frequency of IPSCs occurred at a stable level between 0.5 and $5 \mathrm{~Hz}$ (Fig. 7). The intervals between IPSCs were exponentially distributed (Fig. 8), consistent with the assumption of independent release sites. The IPSCs were inward at hyperpolarized potentials, consistent with $\mathrm{Cl}^{-}$currents caused by the high pipette concentration of $\mathrm{Cl}^{-}$. The IPSCs were not blocked by addition of $100 \mu \mathrm{m} \mathrm{Cd}^{2+}$ to the bath solution (Fig. 9), which has been shown to block calcium currents in cultured leech neurons (Stewart et al., 1989). These data taken together suggest that the synaptic currents represent miniature IPSCs (mIPSCs) caused by spontaneous transmitter release.

The absolute amplitudes of mIPSCs varied from the detection limit of 5 to $70 \mathrm{pA}$ using either the high $\mathrm{KCl}$ or high $\mathrm{CsCl}$ pipette solutions. The mIPSC recordings were analyzed in further detail for stage E11-E12 embryos. In the experiment shown in Figure 10, mIPSCs had a mean amplitude of $17.2 \pm 6.0 \mathrm{pA}$ (Fig. 10A) and a median value of $15.8 \mathrm{pA}$. The mean rise time $(20-80 \%)$ of mIPSCs was $1.88 \pm 0.04 \mathrm{msec}$ (Fig. 10B) and had an exponential decay with a mean time constant of $21.8 \mathrm{msec}( \pm 16.1)$ (Fig. 10D). There did not seem to be any significant differences in the amplitudes $(15.8 \pm 5.5 \mathrm{pA})$, rise times $(2.7 \pm 2.7 \mathrm{msec})$, or decay time constants $(18.0 \pm 12.7)$ in five different recordings with large numbers of events.

There was no correlation between the rise times and the amplitude of IPSCs $\left(r^{2}<0.001\right)$ (Fig. 10C), indicating that the cells were well clamped and that dendritic filtering did not occur (Rall, 1969). Using the high $\mathrm{CsCl}$ solution at E11 or later, there was no significant deterioration in the frequency, amplitude, or decay time of events between the beginning and end of the recording periods (15-90 min), indicating that washout did not

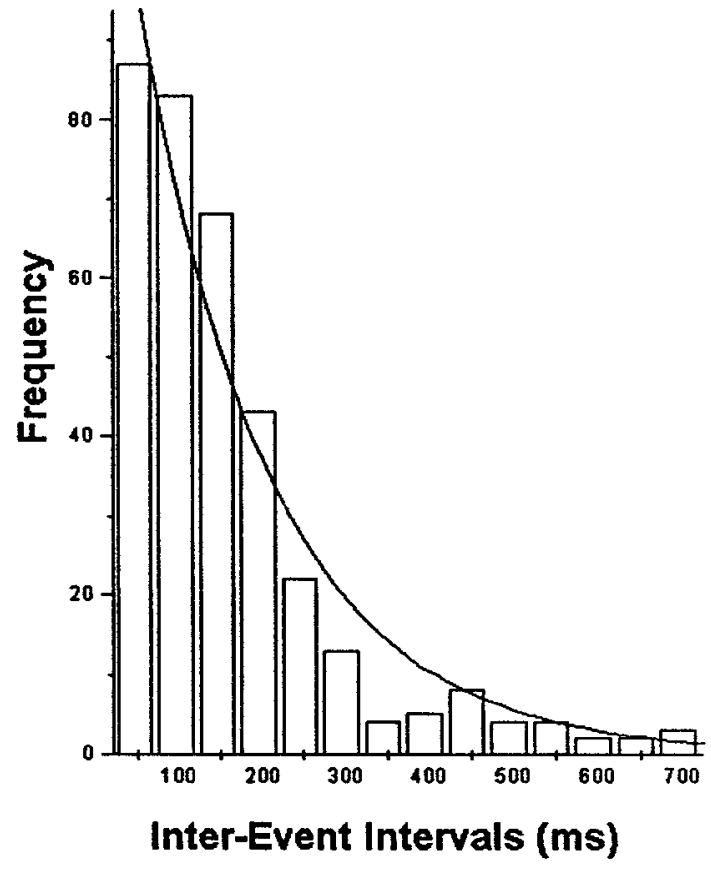

Figure 8. Interevent interval distribution. The frequency of events (i.e., the number occurring within each time bin) recorded from a $\mathrm{P}$ cell is plotted as a function of the interevent interval. The distribution was fit by an exponential function with a time constant of $250 \mathrm{msec}$. Events separated by $<20$ msec were excluded.

affect the events. To be absolutely certain that the washout of intracellular components did not affect the results, we also preformed perforated-patch recordings in which electrical access to the inside of the cell was gained using a cell-attached patch electrode containing nystatin, a pore-forming antibiotic that prevents the loss of nonionic cytoplasmic constituents (Horn and Korn, 1992). The event profiles observed using the high $\mathrm{KCl}$ solution containing ATP and GTP did not seem to differ from those using high $\mathrm{CsCl}$ solution without these compounds, and the perforated-patch experiments confirmed the onset of activity at E11 and the absence of activity in younger stages (data not shown). We therefore concluded that whole-cell recording had no deleterious effects, permitting us to record faithfully the onset of synaptic events.

\section{Lack of evoked release from the embryonic $R$ cell}

Results from the $\mathrm{Cd}^{2+}$ experiment indicated that the activity we detected was attributable to spontaneous release of transmitter. To determine whether evoked release occurred onto $\mathrm{P}$ cells, we stimulated the $\mathrm{R}$ cell that is known to inhibit the $\mathrm{P}$ cells in the adult by opening $\mathrm{Cl}^{-}$channels (Drapeau et al., 1988). Specifically, the R cells were stimulated using a whole-cell patch electrode under current-clamp conditions while recording from ipsilateral $\mathrm{P}$ cells in the same ganglion under voltage-clamp conditions. Neither eliciting single action potentials nor trains of action potentials in the R cell was able to evoke IPSCs in the P neuron in embryos up to E14 ( $n=3$; data not shown). Lessmann and Dietzel (1995a) have shown that step depolarization of the $\mathrm{P}$ cell enhances synaptic input from the $\mathrm{R}$ cell when embryonic neurons are placed in culture. However, we found that step depolarization in the $\mathrm{P}$ cell did not reveal synaptic inputs from the $\mathrm{R}$ cell (data not shown). These results suggest that although 


\section{Control}
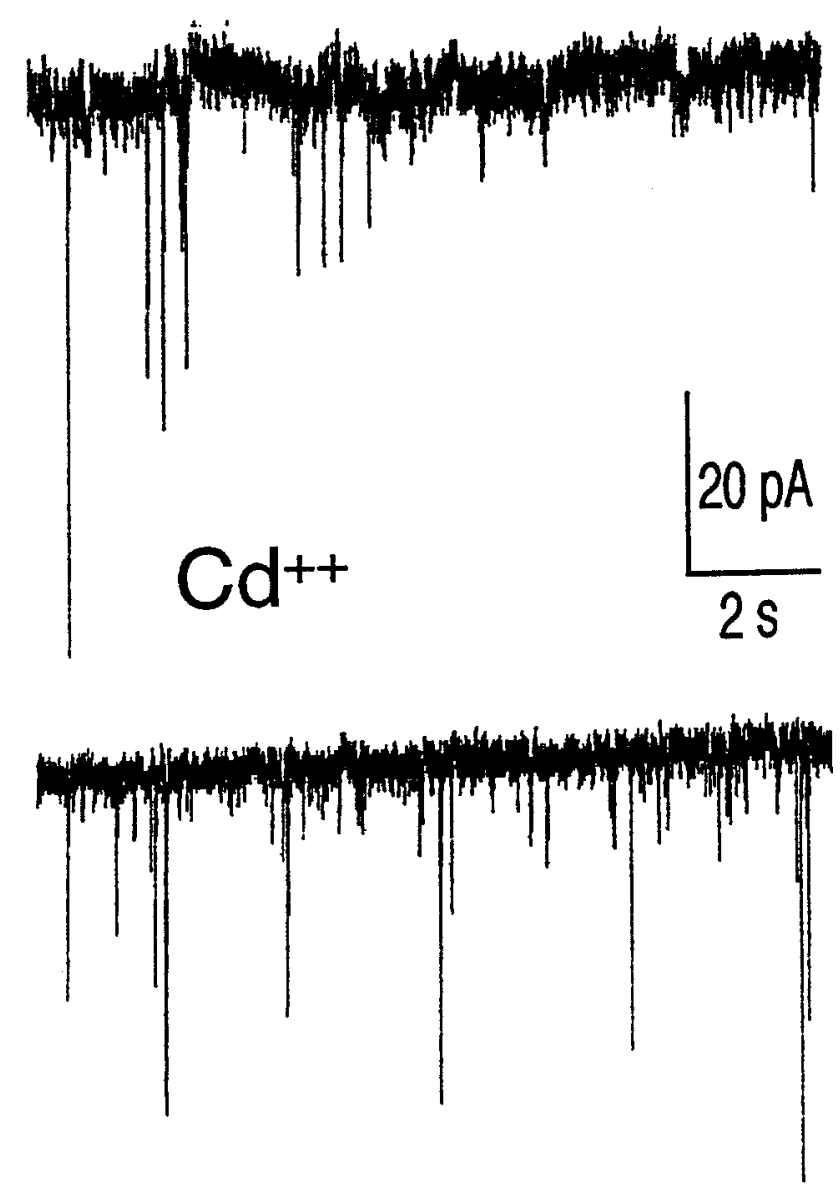

Figure 9. Effects of Cd on spontaneous events. A $10 \mathrm{sec}$ recording from a $\mathrm{P}$ cell shows the spontaneous activity in the absence (top) or presence (bottom) of $100 \mu \mathrm{m} \mathrm{Cd}^{2+}$ added to the bath solution. Cd had no obvious blocking activity on the synaptic events up to $30 \mathrm{~min}$ after its application.

spontaneous release (from unknown partners) starts on E11, evoked release, at least from the R cell, develops later than E14.

\section{DISCUSSION}

We explored the relationship between neurite outgrowth and synapse formation in the central neuropil of the leech embryo. After the growth of primary neurites by the P cell, we observed transient neurites within the neuropil that retracted and appeared to form spurs. After a dormant period, stable secondary branches grew (possibly from the spurs) and became tipped with terminals. At this time, neurites of the $\mathrm{R}$ cell were observed apparently to contact the terminals. Voltage-dependent currents were seen at the earliest stage, but the neurons lacked spontaneous action potentials. Spontaneous synaptic activity was only observed when terminals had formed, before evoked release from the $\mathrm{R}$ cell could be detected.

\section{Early outgrowth preceding synaptogenesis}

The growth cones on primary neurites of the $\mathrm{P}$ cell were either studded with filopodia while in the neuropil or were spike shaped while rapidly growing along nerve tracts. These morphologies have been described in a variety of preparations (Stirling and
Dunlop, 1995) including the leech (Kopp and Jellies, 1993) for exploratory and actively growing neurites, respectively.

The primary branches elaborated fine, transient neurites in the neuropil. Transient neurites have been described as filopodial-like structures in preparations ranging from grasshopper (Taghert et al., 1982) and leech embryos (Kuwada and Kramer, 1983) to mammalian hippocampus (Ziv and Smith, 1996) and brainstem (Saito et al., 1997). Although the function of transient neurites is not known, they are thought to enlarge the effective volume of the neuron and to enhance contact with its neighbors. It has been proposed that not all neurites are necessarily retracted and that those that are lost are retracted by activity-dependent pruning (Lnenicka and Murphey, 1989), whereas those that are retained may develop into stable neurites (Ziv and Smith, 1996). We doubt that either of these mechanisms plays a role in the development of the $\mathrm{P}$ cell. This is because we failed to detect spontaneous electrical activity, and all of the neurites appeared to retract with some forming spurs before entering a dormant period for $\sim 1 \mathrm{~d}$ before synaptogenesis began. It may be that these transient neurites serve no purpose, especially because their presence was not related to the developmental gradient. However, their apparent failure to cross the midline of the ganglion suggests that they respond to their environment. Furthermore, we found that contact (within an hour) between growth cones and neurites of adult $\mathrm{R}$ and $\mathrm{P}$ cells in culture results in the selection of postsynaptic serotonin responses (Ching et al., 1993). Therefore, transient neurites may allow synaptic partners to come into contact and set the stage for synaptogenesis (Haydon and Drapeau, 1995).

The peripheral arbors of both the $\mathrm{P}$ and $\mathrm{R}$ cells have been described in considerable detail. The dorsal $\mathrm{P}$ cell pioneers the dorsal root (Kuwada, 1985) and extends an orthogonal array of branches in the skin (Gan and Macagno, 1995a) at the time that we observed transient branches in the neuropil. The regular appearance, without overlap, of the peripheral branching pattern has been shown to reflect a self-repulsive organizing principle (Gan and Macagno, 1995a; Wang and Macagno, 1997), and this may also apply to the central branches of the same neuron at the same time.

After the retraction of transient neurites, the primary neurites were studded with spurs, likely left by a subset of retracted transients because more transient branches were observed than spurs. Structures resembling spurs have been described in a wide variety of nervous systems (Morest, 1969; Lund et al., 1977, Phelps et al., 1983; Ramoa et al., 1987). In the hippocampus, they have been suggested to be induced by contact with presynaptic neurites as the precursor of postsynaptic spines (Ziv and Smith, 1997). On corticorubral neurons, spurs [or "spine-like dendritic protrusions" (Saito et al., 1997)] have been suggested to be early sites of synapses. However, we found no evidence of functional synapses at this stage, ruling out a synaptogenic role in the P cell. Perhaps the synaptic boutons on spurs in the mammalian CNS are not yet functional nerve endings and are thus transitional structures.

A dormant period of several hours followed without further growth of the P cell in the central neuropil, even though these cells are rapidly growing in the periphery at this stage (Gan and Macagno, 1995a), as shown in the elegant time-lapse study of Wang and Macagno (1997). This suggests a selective downregulation of central growth. Because the later growth of stable neurites occurred in a concerted manner along the developmental gradient, the dormant period may be a prolonged time of consolidation before the next stage of regrowth and synaptogenesis. 
A

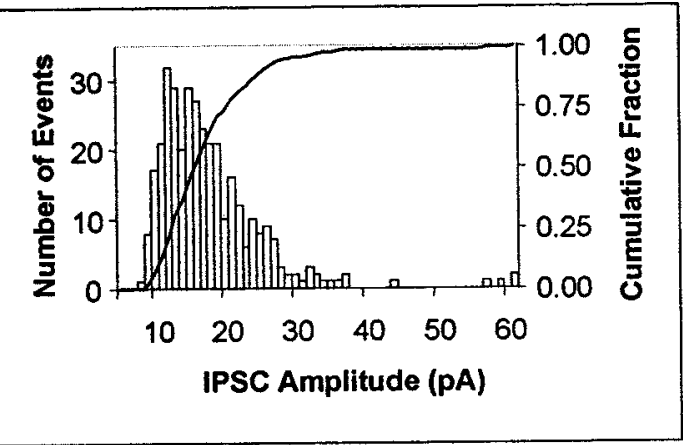

C

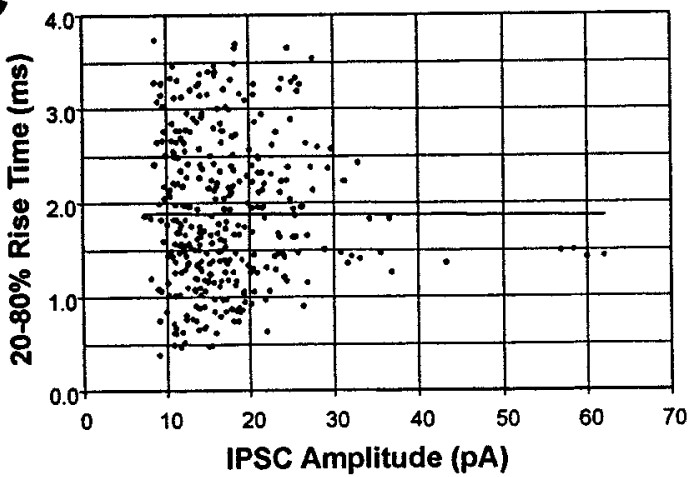

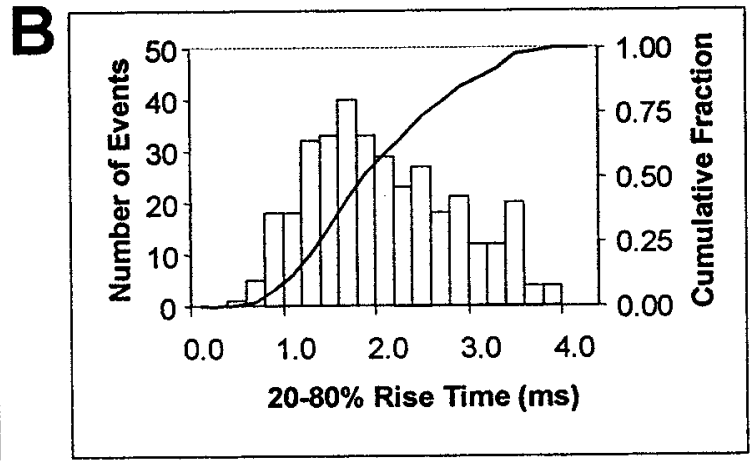

D

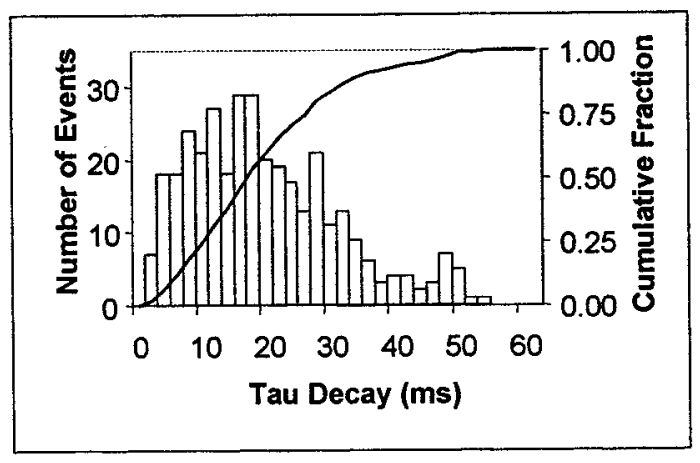

Figure 10. Amplitude, rise time, and decay time distributions of mIPSCs. Whole P cell measurements from a sample experiment for an E13 embryo with high $\mathrm{KCl}$ solution in the recording electrode are shown. The number of events is $350 . A$, Amplitude distribution of events with a mean of $17.2 \mathrm{pA}$ and a median value of $15.8 \mathrm{pA}$. Minimum amplitude was $7.5 \mathrm{pA}(5 \mathrm{pA}$ detection limit), and maximum amplitude was $62.0 \mathrm{pA}$. Cumulative frequency is plotted as a line. An outlying group of high amplitude events ( $>50 \mathrm{pA})$ was observed in all embryos with mIPSCs. $B$, Rise time (20-80\%) distribution with a mean of $1.9 \mathrm{msec}$ and a median value of $1.8 \mathrm{msec}$. Cumulative frequency is plotted as a line. $C$, Scatter plot of rise time (20-80\%) versus peak amplitude. Note the lack of a linear relationship. $D$, Mean time constant of decay (tau decay) of 18.8 msec, with a median value of 16.8 msec. Tau decay was best fit with two exponentials for $\sim 10 \%$ of total events in all embryos.

\section{Stable neurites, terminals, and synapses}

Secondary outgrowth of stable neurites appeared to initiate from the spurs. The morphology of stable neurites was very similar between all animals. Soon after growth, the neurites became tipped with terminal endings. This coincided with the time of apparent contact between the $\mathrm{R}$ and $\mathrm{P}$ cells and with the appearance of spontaneous synaptic currents. The terminals on embryonic P cells resembled single endings of the larger clusters observed in the adult (Muller and McMahan, 1976), where electron microscopic reconstruction has shown that they are the sites of synapses (Muller, 1979). Terminal formation may thus be the morphological precursor of active synapses.

Although voltage-sensitive currents could be evoked from the first extension of primary neurites, spontaneous action potentials were not observed in any of the $\mathrm{P}$ or $\mathrm{R}$ neurons examined even at the stage when mIPSCs were first detected in the P cells. Consistent with this observation, pharmacological experiments have shown that synapse formation can occur in the absence of activity (Jansen and Van Essen, 1975; Anderson and Cohen, 1977; Harris, 1981a,b).

Firing action potentials in the $\mathrm{R}$ cell failed to evoke a synaptic response in the $\mathrm{P}$ cell (up to E14), suggesting that action potentials were not yet coupled to transmitter release. Several possibilities may account for our failure to detect evoked release from the $\mathrm{R}$ cell at the time (E11) that spontaneous release was first detected in the $\mathrm{P}$ cell. The $\mathrm{R}$ cell may have not yet innervated the $\mathrm{P}$ cell. Although we cannot definitely rule out this possibility, it seems unlikely because $\mathrm{R}$ cell neurites had apparently come into contact with $\mathrm{P}$ cell terminals at the time of onset of spontaneous release, and adult (Liu and Nicholls, 1989) and embryonic (Lessmann and Dietzel, 1995a) R cells innervate P cells in culture within hours of coming into contact. Assuming that R cells were releasing transmitter spontaneously although not actively onto $\mathrm{P}$ cells, several other possibilities come to mind. Postsynaptically, a lack of sufficient transmitter receptors is ruled out by the observation of responses to application of serotonin onto cultured $\mathrm{P}$ cells from E10 embryos (Lessmann and Dietzel, 1991), i.e., before synaptogenesis in vivo. Presynaptically, a lack of transmitter in the $\mathrm{R}$ cell is ruled out by immunocytochemical staining for serotonin by this stage of development (Jellies et al., 1987). Also, calcium currents are observed at this stage (Lessmann and Dietzel, 1995b), ruling out a lack of sufficient calcium influx. Taken together, these observations suggest that the coupling of excitation to secretion may limit the development of synaptic transmission. In many other preparations, transmitter receptors have been shown to be expressed before innervation (Spitzer, 1991). The expression of these synaptic components long before synaptogenesis is thus a common feature of embryonic neurons (Haydon and Drapeau, 1995). Interestingly, overexpression of synapsins, a common class of vesicular protein, accelerates the maturation of release properties at cultured Xenopus neuromuscular junctions, 
suggesting that expression of presynaptic elements may limit the maturation of the endplate (Lu et al., 1992; Schaeffer et al., 1994). Perhaps a similar presynaptic factor limits the maturation of central synapses.

Our observation of spontaneous synaptic activity in the P cell in the absence of evoked release from the $\mathrm{R}$ cell is reminiscent of "silent synapses" observed at the developing retinotectal projection in the Xenopus embryo. At these excitatory synapses, postsynaptic depolarization is necessary to reveal and perhaps stabilize presynaptic activity (Wu et al., 1996). This conditional response has been suggested to be retained as a mechanism of plasticity in the adult brain (Malenka and Nicoll, 1997). A similar mechanism of plasticity has been reported for synapses between embryonic R and P neurons in culture (Lessmann and Dietzel, 1995b). There depolarization of the $P$ cell causes an increase in intracellular calcium that in turn potentiates evoked inhibitory responses. Depolarization of the $\mathrm{P}$ cell in vivo failed to reveal synaptic inputs from the $\mathrm{R}$ cell, consistent with a lack of evoked release at this stage. Spontaneous action potentials in the $\mathrm{P}$ cell (perhaps triggered at a later time by sensory transduction in the skin) may be necessary to transform spontaneous synapses into mature responses as a form of activity-dependent synaptic refinement.

Spurs appear to be the sites from which stable neurites with terminal endings are generated during synaptogenesis in the $\mathrm{P}$ cell, which receives inhibitory inputs from nearby partners in the tiny ganglionic neuropil. In the absence of a requirement for long-distance navigation, spurs may be points of growth for stable neurites. Because both spurs and localized inhibitory synapses are abundant in the mammalian CNS, perhaps the spurs represent a primordial organizer for inhibitory synapses in a wide variety of species.

\section{REFERENCES}

Anderson MJ, Cohen MW (1977) Nerve-induced and spontaneous redistribution of acetylcholine receptors on cultured muscle cells. J Physiol (Lond) 268:757-773.

Blagburn JM, Sosa MA, Blanco RE (1996) Specificity of identified central synapses in the embryonic cockroach: appropriate connections form before the onset of spontaneous afferent activity. J Comp Neurol 373:511-528.

Ching S, Catarsi S, Drapeau P (1993) Selection of transmitter responses at sites of neurite contact during synapse formation between identified leech neurons. J Physiol (Lond) 468:425-439.

Conrad GW, Bee JA, Roche SM, Teillet MA (1993) Fabrication of microscalpels by electrolysis of tungsten wire in a meniscus. J Neurosci Methods 50:123-127.

DeRiemer SA, Macagno ER (1989) Quantitative studies of the growth of neuronal arbors. In: Perspectives in neural systems and behavior (Carew TJ, Kelley DB, eds), p 11. New York: Liss.

Drapeau P, Melinyshyn E, Sanchez-Armass S (1988) Contact-mediated loss of the nonsynaptic response to transmitter during reinnervation of an identified leech neuron in culture. J Neurosci 9:2502-2508.

El-Badry HM (1963) Micromanipulators and micromanipulation. New York: Academic.

Fernandez J, Stent GS (1982) Embryonic development of the hirudinid leech Hirudo medicinalis: structure, development and segmentation of the germinal plate. J Embryol Exp Morphol 72:71-96.

Gan W-B, Macagno ER (1995a) Interactions between segmental isoneuronal branches guide the formation of sensory terminal fields. J Neurosci 15:3242-3253.

Gan W-B, Macagno ER (1995b) Developing neurons use a putative pioneer's peripheral arbor to establish their terminal fields. J Neurosci $15: 3254-3262$.

Glazer AN (1988) Fluorescence-based assay for reactive oxygen species: a protective role for creatinine. FASEB J 2:2487-2491.

Goodman CS, Shatz CJ (1993) Developmental mechanisms that gener- ate precise mechanisms of neuronal connectivity. Cell/Neuron [Suppl] 72:77-98.

Harris AJ (1981a) Embryonic growth and innervation of rat skeletal muscles. II. Neural regulation of muscle cholinesterase. Philos Trans R Soc Lond [Biol] 293:279-286.

Harris AJ (1981b) Embryonic growth and innervation of rat skeletal muscles. III. Neural regulation of junctional and extrajunctional acetylcholine receptor clusters. Philos Trans R Soc Lond [Biol] 293:287-314.

Haydon PG, Drapeau P (1995) From contact to connection: early events during synaptogenesis. Trends Neurosci 18:196-201.

Horn R, Korn SJ (1992) Prevention of rundown in electrophysiological recording. Methods Enzymol 207:149-155.

Jansen JKS, Van Essen DC (1975) Reinnervation of rat skeletal muscle in the presence of $\alpha$-bungarotoxin. J Physiol (Lond) 250:651-667.

Jellies J, Loer CM, Kristan WB (1987) Morphological changes in leech Retzius neurons after target contact during embryogenesis. J Neurosci 7:2618-2629.

Katz LC, Shatz CJ (1996) Synaptic activity and the construction of cortical circuits. Science 274:1133-1138.

Kopp DM, Jellies J (1993) Multimorphic growth cones in the embryonic medicinal leech: relationship between shape changes and outgrowth transitions. J Comp Neurol 328:393-405.

Kuwada JY (1985) Pioneering and pathfinding by an identified neuron in the embryonic leech. J Embryol Exp Morphol 86:155-167.

Kuwada JY, Kramer AP (1983) Embryonic development of the leech nervous system: primary axon outgrowth of identified neurons. J Neurosci 3:2098-2111.

Lessmann V, Dietzel ID (1991) Development of serotonin-induced ion currents in identified embryonic Retzius cells from the medicinal leech (Hirudo medicinalis). J Neurosci 11:800-809.

Lessmann V, Dietzel ID (1995a) Two kinetically distinct 5hydroxytryptamine-activated $\mathrm{Cl}^{-}$conductances at Retzius P-cell synapses of the medicinal leech. J Neurosci 15:1496-1505.

Lessmann V, Dietzel ID (1995b) Enhancement of postsynaptic serotonin-activated $\mathrm{Cl}$ - currents by depolarization-induced $\mathrm{Ca} 2+$ entry into leech neurons. Neuroscience 67:525-529.

Liu Y, Nicholls J (1989) Steps in the development of chemical and electrical synapses by pairs of identified leech neurons in culture. Proc R Soc Lond [Biol] 236:253-268.

Lnenicka GA, Murphey RK (1989) The refinement of invertebrate synapses during development. J Neurobiol 20:339-355.

Lu B, Greengard P, Poo M-M (1992) Exogenous synapsin I promotes functional maturation of developing neuromuscular synapses. Neuron 8:521-529.

Lund JS, Boothe CG, Lund RD (1977) Development of neurons in the visual cortex (area 17) of the monkey (Macaca nemestrina): a Golgi study from fetal day 127 to postnatal maturity. J Comp Neurol 176:149-188.

Malenka RC, Nicoll RA (1997) Silent synapses speak up. Neuron 19:473-476.

Morest DK (1969) The growth of dendrites in the mammalian brain. Z Anat Entwicklungsgesch 128:290-317.

Muller KJ (1979) Synapses between neurones in the central nervous system of the leech. Biol Rev 54:99-134.

Muller KJ, McMahan UJ (1976) The shapes of sensory and motor neurones and the distribution of their synapses in ganglia of the leech: a study using intracellular injection of horseradish peroxidase. Proc R Soc Lond [Biol] 194:481-499.

Phelps PE, Adinolfi AM, Levine MS (1983) Development of the kitten substantia nigra: a rapid Golgi study of the early postnatal period. Brain Res 312:1-19.

Rall W (1969) Time constants and electrotonic length of membrane cylinders and neurons. Biophys J 9:1483-1508.

Ramoa AS, Campbell G, Shatz CJ (1987) Transient morphological features of identified ganglion cells in living fetal and neonatal retina. Science 237:522-525.

Saito Y, Song W-J, Murakami F (1997) Preferential termination of corticorubral axons on spine-like dendritic protrusions in developing cat. J Neurosci 17:8792-8803.

Schaeffer E, Alder J, Greengard P, Poo M-M (1994) Synapsin IIa accelerates functional development of neuromuscular synapses. Proc Natl Acad Sci USA 91:3882-3886.

Sineva MV (1944) Observations on the breeding of the medicinal leech. Zool Zh 23:293-303. 
Sineva MV (1949) Biological observations on the propagation of the medicinal leech. Zool Zh 28:213-214.

Spitzer NC (1991) A developmental handshake: neuronal control of ionic currents and their control of neuronal differentiation. J Neurobiol 22:659-673.

Stent GS, Kristan WB, Torrence SA, French KA, Weisblat DA (1992) Development of the leech nervous system. Int Rev Neurobiol 33:109-193.

Stewart RR, Nicholls JG, Adams WB (1989) $\mathrm{Na}^{+}, \mathrm{K}^{+}$and $\mathrm{Ca}^{2+}$ currents in identified leech neurones in culture. J Exp Biol 141:1-20.

Stirling VR, Dunlop SA (1995) The dance of the growth cones-where to next? Trends Neurosci 18:111-115.

Taghert PH, Bastiani MJ, Ho RK, Goodman CS (1982) Guidance of pioneer growth cones: filopodial contacts and coupling revealed with an antibody to Lucifer yellow. Dev Biol 94:391-399.
Tessier-Lavigne M, Goodman CS (1996) The molecular biology of axon guidance. Science 274:1123-1133.

Wang H, Macagno ER (1997) The establishment of peripheral sensory arbors in the leech: in vivo time-lapse studies reveal a highly dynamic process. J Neurosci 17:2408-2419.

Wenning A, Calabrese RL (1991) Mechanism of $\mathrm{Cl}^{-}$sensitivity in internal ion receptors of the leech: an inward current gated off by $\mathrm{Cl}^{-}$in the nephridial nerve cells. J Comp Physiol [A] 168:53-61.

Wolszon LR, Passani BM, Macagno ER (1995) Interactions during a critical period inhibit bilateral projections in embryonic neurons. J Neurosci 15:1506-1515.

Wu G-Y, Malinow R, Cline HT (1996) Maturation of a central glutamatergic synapse. Science 274:972-976.

Ziv NE, Smith SJ (1996) Evidence for a role of dendritic filopodia in synaptogenesis and spine formation. Neuron 17:91-102. 